\title{
Linfossarcoma em bovinos no Agreste Meridional de Pernambuco
}

\author{
Alonso P. Silva Filho ${ }^{2 *}$, José Augusto B. Afonso ${ }^{3}$, José Cláudio de A. Souza ${ }^{4}$, Franklin Riet \\ Correa $^{5}$, Antônio F. Dantas ${ }^{5}$, Alexandre C. Dantas ${ }^{3}$, Nivaldo de A. Costa ${ }^{3}$ e Carla L. Mendonça ${ }^{3}$
}

\begin{abstract}
Silva Filho A.P., Afonso J.A.B., Souza J.C.A., Riet-Correa F., Dantas A.F., Dantas A.C., Costa N.A. \& Mendonça C.L. 2011. [Lymphosarcoma in cattle from the hinterland of Pernambuco state.] Linfossarcoma em bovinos no Agreste Meridional de Pernambuco. Pesquisa Veterinária Brasileira 31(7):591-597. Clínica de Bovinos, Campus Garanhuns, Universidade Federal Rural de Pernambuco, Av. Bom Pastor s/n, Boa Vista, Garanhuns, PE 55292-270, Brazil. E-mail: alonsopsfilho@yahoo.com.br

The article reports epidemiological data, clinical signs, and laboratory and pathological findings in 24 cattle with enzootic bovine leukosis observed in the Clinic of Garanhuns, at the Federal Rural University of Pernambuco. The 24 cases represented $0.5 \%$ of 4,758 cattle examined from 2000 to 2010 . The disease affected $22(91.7 \%)$ females and two males. Twenty one of the animals were dairy (six Holstein, 13 girolando, one Brown Swiss and one Jersey), and three were for meat production (Nelore). Twenty three animals were 3-8 years of age and one was younger. All were raised in confinement or semi-confinement. All animals showed enlarged superficial lymph nodes. Other frequent clinical signs were hyporexia, decreased milk production, progressive weight loss, dehydration, hypomotility of the fore stomachs, and altered scant feces. Exophthalmia, dyspnea, and enlarged uterus were observed with less frequency. Leukocytosis (mean of 34,082 leukocytes/ $\mu \mathrm{L}$ ) with lymphocytosis $(21,814$ lymphocytes $/ \mu \mathrm{L})$ and neutrophilia $(10,906$ lymphocytes $/ \mu \mathrm{L})$ was observed in the white blood count. Thirteen bovines were necropsied and 11 were slaughtered. Gross lesions were observed on the superficial lymph nodes of all animals necropsied. Six had lesions in the mesenteric lymph nodes, six in the gut, three in the abomasum, two in the uterus, one in the heart, one in the rumen, one in heart, and one in the liver. Due to the importance of enzootic bovine leukosis it is necessary for the farmers to introduce animals free of the disease and to establish a strict health policy for its control.
\end{abstract}

INDEX TERMS: Enzootic bovine leukosis, leukemia, lymphocytosis, neoplasm.

RESUMO.- Neste trabalho são descritos os sinais clínicos, patologia clínica e patologia de 24 bovinos com leucose bovina enzoótica atendidos na Clínica de Bovinos de Garanhuns da Universidade Federal Rural de Pernambuco. Esses casos representaram $0,5 \%$ de 4.758 bovinos atendidos entre os anos de 2000 e 2010 . A doença afetou 22 (91,7\%) fêmeas e dois machos. Vinte e um animais $(87,5 \%)$ eram de raças leiteras (seis Holandês, 13 Girolando, um Jersey e um Pardo Suíça) e

\footnotetext{
${ }^{1}$ Recebido em 19 de janeiro de 2011.

Aceito para publicação em 23 de março de 2011.

${ }^{2}$ Mestrando do Programa de Ciências Veterinária, Universidade Federal Rural de Pernambuco (UFRPE), Avenida Bom Pastor s/n, Clínica de Bovinos, Garanhuns, PE 55292-901, Brasil. *Autor para correspondência: alonsopsfilho@yahoo.com.br

${ }^{3}$ Clínica de Bovinos de Garanhuns, UFRPE, Cx. Postal 152, Garanhuns, PE.

${ }^{4}$ Unidade Acadêmica de Garanhuns, UFRPE, Garanhuns, PE.

${ }^{5}$ Universidade Federal de Campina Grande, Campus Patos, Cx. Postal 64, Patos, PB 58700-970, Brasil.
}

três $(12,5 \%)$ eram da raça Nelore. Vinte e três animais $(95,8 \%)$ tinham idade entre 3 e 8 anos e um era mais jovem. Todos eram criados em regime de confinamento ou semiconfinamento. Clinicamente todos os animais apresentaram aumento dos linfonodos superficias. Outros sinais frequentes foram hiporexia, diminuição da produção de leite, emagrecimento progressivo, escore corporal baixo, desidratação, hipomotilidade dos pré-estômagos e fezes alteradas e em pouca quantidade. Com menor frequência foram observados exoftalmia, dispneia e aumento de volume do útero. No leucograma foi constatada leucocitose média de $34.082 / \mu \mathrm{L}$, com linfocitose de $21.814 / \mu \mathrm{L}$ e neutrofilia de $10.906 / \mu \mathrm{L}$. Treze animais foram necropsiados e os demais foram enviados pelos proprietários para o abate. Dos treze animais abatidos todos apresentaram lesões nos linfonodos superficiais, seis nos linfonodos mesentéricos, seis no intestino, três no abomaso, um no coração, um no fígado, um no rúmen, um no útero e um no rim. Diante da importância desta enfermidade 
e dos prejuízos causados pela mesma é necessário alertar produtores sobre os cuidados a serem tomados durante a aquisição de animais, assim como da necessidade de implantar medidas que evitem a difusão da doença entre as fazendas.

TERMOS DE INDEXAÇÃO: Leucose bovina enzoótica, linfocitose, neoplasma.

\section{INTRODUÇÃO}

O linfossarcoma é uma das formas de apresentação da Leucose Enzoótica Bovina (LEB) e se trata de uma enfermidade infectocontagiosa, pluri-sintomática, com evolução crônica, manifestando-se de dois a cinco anos após a infecção, acometendo bovinos, principalmente os mantidos em regime intensivo. É causada por um vírus da família Retroviridae, subfamília Oncovirinae e gênero Deltaretrovirus, que afeta a linhagem celular linfóide desses animais, determinando o aumento do número de linfócitos B circulantes. Além desta, a doença pode se manifestar de outras duas formas: a aleucêmica, com presença de anticorpos; e a linfocitose persistente (LP). Na primeira forma o bovino não apresenta sinais clínicos e torna-se um importante transmissor do vírus. De modo geral $30 \%$ dos bovinos infectados desenvolvem LP (Ferrer 1979, Ferrer 1980, Burny et al. 1985, Johnson \& Kaneene 1992, Schwartz \& Levy 1994, Braga \& Laan 2001).

0 virus é prevalente em diversos estados do Brasil e no mundo. Apesar dos bovinos serem os hospedeiros primários e a espécie mais suscetível, o agente possui a capacidade de infectar, in vitro, células de muitas outras espécies, inclusive as do homem (Dahlberg 1988). Pela infecção experimental, o vírus produz efeito patogênico em várias espécies animais, incluindo ovinos, caprinos e algumas espécies não-ruminantes (Burny et al. 1985, Dahlberg 1988, Murphy et al. 1999, Leite et al. 2001, Amoril 2005, Birgel Junior et al. 2006).

A infecção pelo vírus da LEB compromete o sistema imunológico dos bovinos levando a imunossupressão, ocasionando redução na produtividade e ocorrência de infecções secundárias. Os animais infectados devem ser descartados precocemente antes mesmo do aparecimento de qualquer sinal clínico relacionado com a LEB. Em rebanhos infectados, a produção de leite é menor e a taxa de descarte é maior, quando comparados com rebanhos livres da doença, desencadeando prejuízos econômicos para a pecuária bovina de leite, principalmente quando aparece a forma de linfossarcoma (Trainin et al. 1996). Nestes casos são observadas manifestações clínicas por transtornos em órgãos ou sistemas atingidos, originando problemas circulatórios, respiratórios, digestivos, reprodutivos, urinários e/ou neurológicos (Silva et al. 2008).

Estudos realizados sobre a importância econômica dessa enfermidade nos Estados Unidos demonstraram uma perda de 42 milhões de dólares relacionados à produção leiteira (Da et al. 1993). No Brasil a LEB foi descrita pela primeira vez por Rangel \& Machado (1943), e se encontra distribuída em todo território nacional. Trabalhos com bovinos leiteiros na região do Nordeste encontraram uma prevalência de 29,94\%, sendo registrada em praticamente todos os Estados (Melo 1991, Birgel et al. 1999, Silva 2001, Mendes 2002, Matos et al. 2005). No Agreste meridional de Pernambuco, a prevalência foi de 15,1\% (Melo 1991, D’angelino et al. 1998).
Sua importância econômica reside, além das perdas já citadas anteriormente, às barreiras ao comércio internacional de animais, de sêmen e embriões, já que a maior parte dos países importadores exige que os animais não estejam infectados (OIE 2003).

Sabe-se, que a principal forma de disseminação da LEB está relacionada às práticas de manejo adotadas nas propriedades, principalmente as mais tecnificadas e, consequentemente, possuem os maiores índices de produtividade. Isso se deve ao manejo intenso utilizando palpação retal, imunização, transfusão sanguínea e cirurgias, as quais favorecem a transferência de linfócitos infectados. Há, ainda, a ação mecânica de tabanídeos nos meses com temperatura elevada, além da introdução de animais de importação infectados, utilizados para o melhoramento genético dos rebanhos (Burny et al. 1988, Johnson \& Kaneene 1992, Hubner et al. 1997, Braga \& Laan 2001).

0 presente artigo teve como objetivo relatar as formas clínicas de manifestação de linfossarcoma em bovinos positivos para LEB, atendidos na Clínica de Bovinos de Garanhuns da Universidade Federal Rural de Pernambuco (CBG-UFRPE).

\section{MATERIAL E MÉTODOS}

Para esse estudo foram utilizados os dados epizootiológicos e exames clínico-laboratoriais e anatomopatológicos obtidos das fichas clínicas e laudos de necropsia de 24 bovinos com diagnóstico positivo para LEB sob a forma de linfossarcoma, de um total de 4.758 bovinos atendidos na CBG-UFRPE, durante o período de 2000-2010. 0 exame clínico procedeu-se de acordo com Dirksen (1993).

A avaliação hematológica foi realizada em 22 dos 24 bovinos. 0 sangue foi coletado em tubos de vidro com anticoagulante, seguindo a metodologia proposta por Jain (1993). A dosagem do teor de cloreto no fluido ruminal de três bovinos com suspeita de obstrução intestinal por leucose foi processada através do método colorimétrico empregando-se kits comerciais, segundo Afonso \& Costa (2007).

Foram coletadas amostras de soro de 18 dos 24 bovinos suspeitos de leucose, as quais foram submetidas à prova de imunodifusão em gel de ágar (IDGA), com antígeno glicoprotéico para a detecção de anticorpos contra o LEB, conforme técnica descrita por Flores et al. (1988).

Em três animais suspeitos de obstrução intestinal por linfossarcoma foi realizada laparotomia exploratória no flanco direito de acordo com a técnica de Fubini \& Trent (2004). Nos casos em que foi confirmada a presença de nodulações em várias regiões do trato digestivo, ou quando os animais apresentavam condição clínica precária foi realizada a eutanasia. Os animais eutanasiados e os que morreram espontaneamente foram necropsiados e amostras de linfonodos e das nodulações encontradas em diversos órgãos foram coletadas, fixadas em formalina a $10 \%$ e coradas pela técnica de hematoxilina-eosina (HE) para observação em microscópio ótico. Onze bovinos com diagnóstico confirmado mediante IDAG e exames clínico-laboratoriais, foram encaminhados para o abate pelos proprietários, não sendo possível a realização da necropsia.

A análise estatística dos dados foi realizada de forma descritiva, determinando as distribuições de freqüências das variáveis relativas analisadas, conforme Curi (1997).

\section{RESULTADOS}

Na CBG-UFRPE, a LEB na forma de linfossarcoma representou $0,5 \%$ da casuística entre os anos de 2000 e 2010, obser- 
vado 24 casos em um total de 4.758 bovinos atendidos. Dos bovinos afetados $22(91,7 \%)$ eram fêmeas. Vinte e um animais $(87,5 \%)$ eram de raças leiteiras (seis Holandês, 13 Girolando, um Jersey e um Pardo Suíça) e três (12,5\%) de corte (Nelore). A maioria dos animais (95,8\%) tinha idade entre três e oito anos $(20,8 \%$ de $3-4$ anos; $54,2 \%$ de 5-6 anos e $20,8 \%$ de $7-8$ anos) e apenas um animal tinha um ano e meio de idade. Todos os bovinos eram criados em regime de confinamento ou semi-confinamento.

Os principais sinais clínicos observados nos bovinos acometidos foram: apatia, diminuição do apetite, queda na produção de leite, emagrecimento progressivo, cansaço, além de prostração, desidratação e linfonodos superficiais aumentados, principalmente os sub-mandibulares, pré-escapulares, subilíacos e supra-mamários. A exoftalmia por linfossarcoma dos linfonodos e tecidos retrobulbares foi observada em quatro animais (Fig. 1A); nestes animais constatou-se ainda presença de nodulações na região cervical (linfonodos satélites). Durante a palpação retal foi possível identificar pre- sença de nodulações em apenas três bovinos, essas massas se apresentaram de consistência firme e tamanho variando entre 10-40 cm de diâmetro na cavidade abdominal, localizados nos linfonodos mesentéricos, alças intestinais e na região dorsal do útero (Fig. 1 D e I). Os animais com suspeita de obstrução intestinal apresentavam motilidade gástrica reduzida e em alguns casos as fezes estavam alteradas de coloração enegrecidas, com presença de muco e em pouca quantidade. Em dois animais a presença de uma massa tumoral extensa na região dorsal do útero provocou complicações no momento do parto, sendo necessária a realização de cesariana. A distribuição dos sinais clínicos em 24 bovinos se apresentam no Quadro 1.

Nos exames laboratoriais realizados, observou-se que não houve alteração na série vermelha da avaliação hematológica, porém no leucograma foi constatada leucocitose com uma média de 34.082 leucócitos/ $\mu \mathrm{L}$, com linfocitose (21.814 linfócitos $/ \mu \mathrm{L}$ ) e neutrofilia (10.906 neutrófilos/ $\mu \mathrm{L})$. A prova de IDAG deu positiva para todos os 18 bovinos testados (Quadro



Fig.1. Diferentes tipos de linfossarcomas encontrados nos bovinos atendidos na CBG-UFRPE: (A) no olho direito, (B) na serosa do abomaso, (C) na mucosa abomasal, (D,E) na cadeia mesentérica, visão externa e interna respectivamente, (F) na serosa do duodeno, (G) na zona cortical e medular dos rins, (H) coração: no interior do ventrículo direito e (I) na região do corpo do útero. 
Quadro 1. Principais achados clínicos encontrados nos bovinos com linfossarcoma, atendidos na CBG-UFRPE

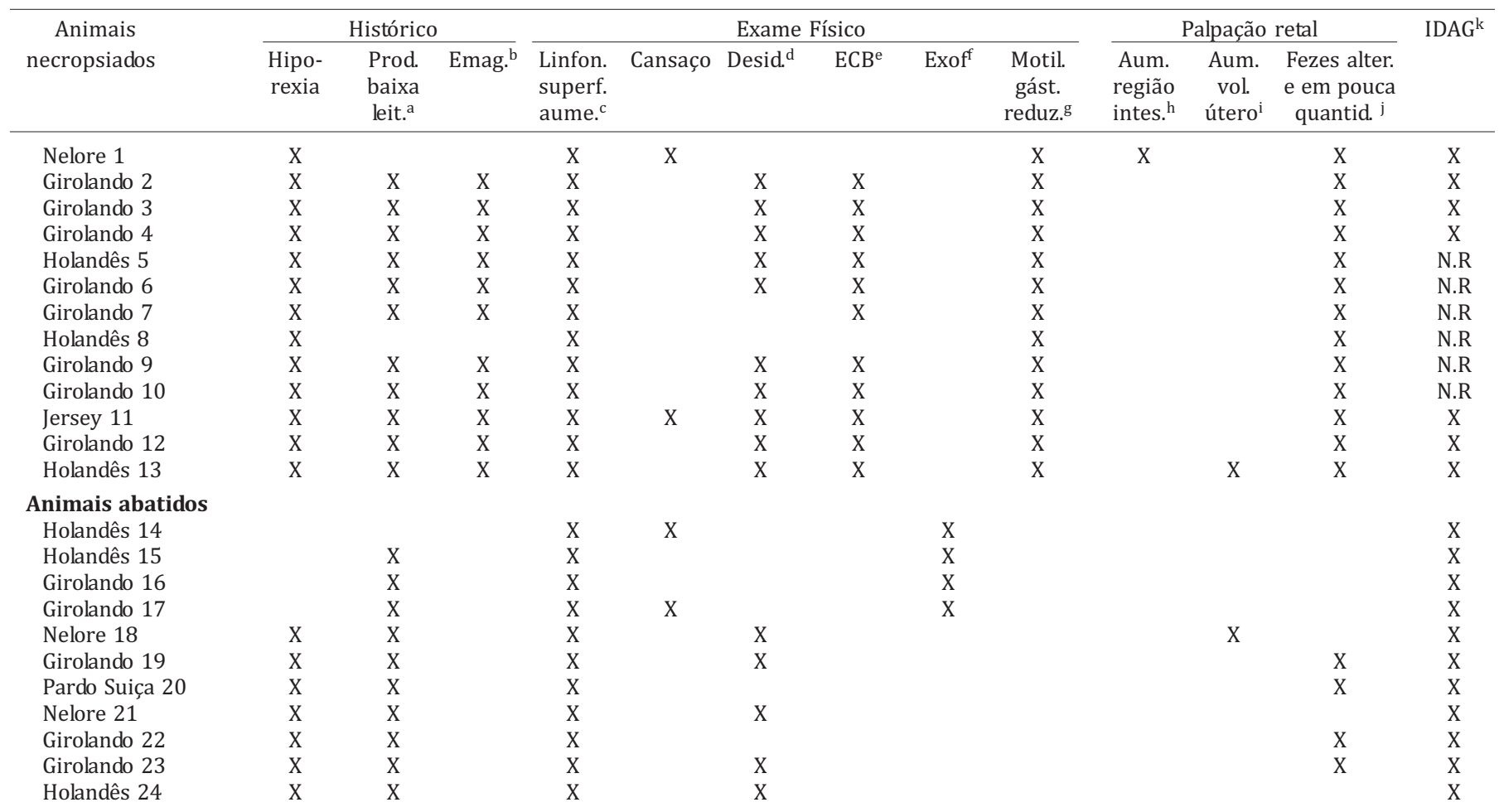

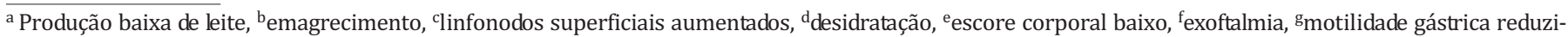

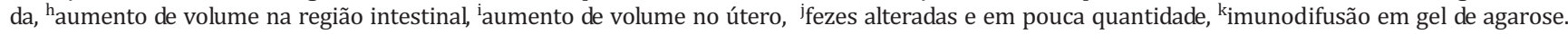

1). Na avaliação do fluido ruminal observou-se elevação dos índices do teor de cloreto, com valor médio de $57 \mathrm{mEq} / \mathrm{L}$, em três animais com suspeita de obstrução intestinal. Nestes casos foi necessária a realização de laparotomia exploratória observando presença de inúmeros nódulos de coloração branco-amarelada, de tamanhos variados $(10-40 \mathrm{~cm})$, consistência firme, com formato irregular e sem sensibilidade, que se estendiam a determinados segmentos da cadeia mesentérica, intestino delgado, região pilórica e abomaso (Fig.1B, D,E).

$\mathrm{Na}$ necropsia, realizada em 13 dos 24 bovinos afetados, havia linfonodos superficiais aumentados de tamanho (submandibulares, pré-escapulares, sub-ilíacos e supramamários). Observavam-se massas, algumas firmes outras friáveis, amarela-

Quadro 2. Principais achados de necropsia encontrados nos bovinos com linfossarcoma, atendidos na CBG-UFRPE

\begin{tabular}{|c|c|c|c|c|c|c|c|c|c|}
\hline \multirow{2}{*}{$\begin{array}{l}\text { Animais } \\
\text { necrop- } \\
\text { siados }\end{array}$} & \multirow{2}{*}{$\begin{array}{c}\text { Cora- } \\
\text { ção }\end{array}$} & \multirow{2}{*}{$\begin{array}{l}\text { Linfo- } \\
\text { nodos } \\
\text { superf. }\end{array}$} & \multicolumn{7}{|c|}{ Órgãos abdominais } \\
\hline & & & $\begin{array}{l}\text { Mesen- } \\
\text { térico }\end{array}$ & Rúmen & $\begin{array}{l}\text { Abo- } \\
\text { maso }\end{array}$ & $\begin{array}{c}\text { Intes- } \\
\text { tino }\end{array}$ & $\begin{array}{c}\text { Fíga- } \\
\text { do }\end{array}$ & Rins & Útero \\
\hline Nelore 1 & $X$ & $X$ & X & & & & & $\mathrm{X}$ & \\
\hline Girolando 2 & & $\mathrm{X}$ & $\mathrm{X}$ & & & & & & \\
\hline Girolando 3 & & $\mathrm{X}$ & $\mathrm{X}$ & & & & & & \\
\hline Girolando 4 & & $\mathrm{X}$ & $\mathrm{X}$ & & & & & & \\
\hline Holandês 5 & & $\mathrm{X}$ & $\mathrm{X}$ & & $\mathrm{X}$ & & & & \\
\hline Girolando 6 & & $\mathrm{X}$ & & & $\mathrm{X}$ & & & & \\
\hline Girolando 7 & & $\mathrm{X}$ & $\mathrm{X}$ & & & & & & \\
\hline Holandês 8 & & $\mathrm{X}$ & & $\mathrm{X}$ & & $\mathrm{X}$ & & & \\
\hline Girolando 9 & & $\mathrm{X}$ & & & & $\mathrm{X}$ & & & \\
\hline Girolando 10 & & $\mathrm{X}$ & & & & $\mathrm{X}$ & & & \\
\hline Jersey 11 & & $\mathrm{X}$ & & & & $\mathrm{X}$ & $\mathrm{X}$ & & \\
\hline Girolando 12 & & $\mathrm{X}$ & & & & $\mathrm{X}$ & & & \\
\hline Holandês 13 & & $\mathrm{X}$ & & & $\mathrm{X}$ & $\mathrm{X}$ & & $\mathrm{X}$ & $\mathrm{X}$ \\
\hline
\end{tabular}

a Linfonodos superficiais, ${ }^{\mathrm{b}}$ linfonodos mesentéricos. das com pontos avermelhados distribuídas em órgaõs da cavidade abdominal. Em um animal observou-se na face visceral do rúmen uma grande massa nodular de aproximadamente $18 \mathrm{~cm}$ de diâmetro. Na serosa e mucosa do abomaso de três animais havia nodulações de superfície irregular. No trato intestinal de seis animais foram observadas: massas nodulares de formas e tamanhos variados, de consistência macia e coloração amarelada (Fig.1B,C,F); linfonodos mesentéricos aumentados, formando entre si aglomerado de massas nodulares de consistência firme, localizados em algumas regiões como o jejuno e cavidade pélvica próximo ao íleo; e nodulações, excessivamente aumentadas, de forma ovalada, com aproximadamente $40 \mathrm{~cm}$ de diâmetro (Quadro 2).

Linfossarcomas foram observados em outros órgãos. Nos rins de dois animais as lesões caracterizam-se por áreas esbranquiçadas na superfície e de tamanhos variados, ao corte invadia o parênquima e extendia-se a região da medular de algumas lobulações (Fig.1G). 0 fígado de um animal encontrava-se de consistência mais friável, aumentado, com pontos amarelados e enegrecidos por toda a superfície. 0 coração de um bovino apresentava uma massa exuberante de superfície irregular, coloração amarelo-avermelhada e de consistência friável no ventrículo direito (Fig.1H).

A microscopia revelou uma distribuição bem característica de aglomerados de linfócitos neoplásicos em diferentes órgãos, linfóides e não linfóides. Estas células caracterizavam-se por serem pequenas, arredondadas, com citoplasma escasso, núcleo grande hipercromático e nucléolo central evidente. Havendo ainda moderado pleomorfismo e várias figuras mitóticas. Observaram-se, também, linfócitos neoplásicos infiltrando principalmente a região medular, se estendendo até a cortical dos 
Quadro 3. Avaliação hematológica dos bovinos que apresentaram linfossarcomas, atendidos CBG-UFRPE

\begin{tabular}{|c|c|c|c|c|c|c|c|c|c|c|c|c|c|}
\hline \multirow{2}{*}{$\begin{array}{l}\text { Número } \\
\text { de animais }\end{array}$} & \multicolumn{13}{|c|}{ Parâmetro hematológico } \\
\hline & $\begin{array}{c}\mathrm{He}^{\mathrm{a}} \\
\mu \mathrm{l}\end{array}$ & $\begin{array}{l}\mathrm{Ht}^{\mathrm{b}} \\
(\%)\end{array}$ & $\begin{array}{c}\mathrm{Hb}^{\mathrm{c}} \\
(\mathrm{g} / \mathrm{dL})\end{array}$ & $\begin{array}{l}\mathrm{VCM}^{\mathrm{d}} \\
(f \mathrm{~L})\end{array}$ & $\begin{array}{c}\mathrm{CHCM}^{\mathrm{e}} \\
(\%)\end{array}$ & $\begin{array}{c}\mathrm{PPt}^{\mathrm{f}} \\
(\mathrm{g} / \mathrm{dL})\end{array}$ & $\begin{array}{c}\mathrm{FP}^{\mathrm{g}} \\
(\mathrm{mg} / \mathrm{dL})\end{array}$ & $\begin{array}{c}\text { LEUC }^{\mathrm{h}} . \\
\mu \mathrm{L}\end{array}$ & $\begin{array}{l}\text { Linf. }^{i} \\
\mu \mathrm{L} / \%\end{array}$ & $\begin{array}{c}\text { Seg. }{ }^{j} \\
\mu \mathrm{L} / \%\end{array}$ & $\begin{array}{l}\text { Bast. }^{k} \\
\mu \mathrm{L} / \%\end{array}$ & $\begin{array}{l}\text { Eosi. }^{1} \\
\mu \mathrm{L} / \%\end{array}$ & $\begin{array}{l}\text { Mon. }^{\mathrm{m}} \\
\mu \mathrm{L} / \%\end{array}$ \\
\hline $\mathrm{A} 1$ & 6.7 & $28 \%$ & 9,5 & 41,8 & 33,9 & 9,4 & 600 & 44.050 & $\begin{array}{l}29.954 \\
(68 \%)\end{array}$ & $\begin{array}{l}11.894 \\
(27 \%)\end{array}$ & & $2 \%$ & $3 \%$ \\
\hline $\mathrm{A} 2$ & 5.1 & $24 \%$ & 8,3 & 47 & 34,9 & 10,4 & 1000 & 13.200 & $\begin{array}{c}9.636 \\
(73 \%)\end{array}$ & $\begin{array}{l}3.036 \\
(23 \%)\end{array}$ & & $1 \%$ & $3 \%$ \\
\hline A3 & 5.3 & $36 \%$ & & 67,8 & & 10,3 & 1000 & 15.950 & $\begin{array}{l}7.497 \\
(47 \%)\end{array}$ & $\begin{array}{c}7.497 \\
(47 \%)\end{array}$ & & $1 \%$ & $5 \%$ \\
\hline A5 & 5.6 & $28 \%$ & 9,6 & 49,3 & 34 & 7,8 & 400 & 24.600 & $\begin{array}{l}16.728 \\
(68 \%)\end{array}$ & $\begin{array}{l}6.396 \\
(26 \%)\end{array}$ & & $9 \%$ & $1 \%$ \\
\hline A6 & 7,1 & $29 \%$ & 10,6 & 40,8 & 34,4 & 7,7 & 700 & 23.950 & $\begin{array}{l}19.639 \\
(82 \%)\end{array}$ & $\begin{array}{c}3.593 \\
(15 \%)\end{array}$ & & $2 \%$ & $1 \%$ \\
\hline A7 & 6,8 & $28 \%$ & 10 & 40,9 & 35,7 & 9,8 & 1.300 & 25.150 & $\begin{array}{l}15.090 \\
(60 \%)\end{array}$ & $\begin{array}{l}9.306 \\
(37 \%)\end{array}$ & $1 \%$ & & $1 \%$ \\
\hline A11 & 7,1 & $29 \%$ & 11,1 & 40,5 & 38,5 & 8,8 & 600 & 14.200 & $\begin{array}{l}8.946 \\
(63 \%)\end{array}$ & $\begin{array}{l}4.544 \\
(32 \%)\end{array}$ & $2 \%$ & & $3 \%$ \\
\hline $\mathrm{A} 12$ & 7,7 & $31 \%$ & 10,9 & 40,2 & 35,45 & 6,5 & 400 & 23.350 & $\begin{array}{l}14.944 \\
(64 \%)\end{array}$ & $\begin{array}{c}7.939 \\
(34 \%)\end{array}$ & & $1 \%$ & $1 \%$ \\
\hline A13 & 7 & $27 \%$ & 9,5 & 38,4 & 35,2 & 7,5 & 800 & 14.650 & $\begin{array}{l}5.714 \\
(39 \%)\end{array}$ & $\begin{array}{l}8.644 \\
(59 \%)\end{array}$ & $1 \%$ & & $1 \%$ \\
\hline A14 & 8,1 & $36 \%$ & 11,23 & 44,1 & 31,2 & 6,4 & 700 & 17.100 & $\begin{array}{c}6.327 \\
(37 \%)\end{array}$ & $\begin{array}{l}10.431 \\
(61 \%)\end{array}$ & & & $2 \%$ \\
\hline A15 & 5,8 & $27 \%$ & 9,5 & 46 & $35 \%$ & 8,4 & 600 & 15.000 & $\begin{array}{l}10.650 \\
(71 \%)\end{array}$ & $\begin{array}{l}2.400 \\
(16 \%)\end{array}$ & & $6 \%$ & $7 \%$ \\
\hline A16 & 6,3 & $28 \%$ & 8,4 & 44,4 & 30,1 & 6,6 & 400 & 90.850 & $\begin{array}{l}72.680 \\
(80 \%)\end{array}$ & $\begin{array}{l}14.536 \\
(16 \%)\end{array}$ & $1 \%$ & & $3 \%$ \\
\hline A22 & 2,9 & $15 \%$ & 4,4 & 51,9 & 29,2 & 5,6 & 300 & 57.150 & $\begin{array}{l}49.721 \\
(87 \%)\end{array}$ & $\begin{array}{l}5.144 \\
(9 \%)\end{array}$ & & $2 \%$ & $4 \%$ \\
\hline $\begin{array}{l}\text { Valor } \\
\text { médio }\end{array}$ & 6,5 & $28 \%$ & 9,2 & 45,1 & 31,8 & 7,9 & 682 & 34.082 & $\begin{array}{l}21.813 \\
(64 \%)\end{array}$ & $\begin{array}{l}10.906 \\
(32 \%)\end{array}$ & $0,48 \%$ & $2 \%$ & $1,5 \%$ \\
\hline Ref. $^{N}$ & $5-10$ & $24-46$ & $8-15$ & $40-60$ & $30-36$ & $7-8.5$ & $300-700$ & $\begin{array}{l}4.000- \\
12.000\end{array}$ & $\begin{array}{c}2500-7500 \\
(45-75 \%)\end{array}$ & $\begin{array}{l}600-4000 \\
(15-45 \%)\end{array}$ & $\begin{array}{c}0-120 \\
(0-2 \%)\end{array}$ & $\begin{array}{c}0-2400 \\
(0-20 \%)\end{array}$ & $\begin{array}{l}25-840 \\
(2-7 \%)\end{array}$ \\
\hline
\end{tabular}

${ }^{a}$ Hemácia, bhematócrito, 'chemoglobina, d volume corpuscular médio, ${ }^{\mathrm{e}}$ concentração de hemoglobina corpuscular média, ${ }^{\mathrm{f}}$ proteína plasmática total, g fibrinogênio plasmático, hleucócitos, 'ilinfócitos, i segmentados, ${ }^{\mathrm{k}}$ bastonetes, ${ }^{\mathrm{l}}$ eosinófilo, ${ }^{\mathrm{m}}$ monócito, ${ }^{\mathrm{n}}$ Kramer (2000).

linfonodos, com perda da arquitetura normal do órgão, além de serem observados na superfície epicárdica e entre as fibras cardíacas, causando separação ou distensão dos feixes das miofibras.

\section{DISCUSSÃO}

Estudos de soro-prevalência realizados por Melo (1991) ratificaram a existência da LEB no Agreste meridional de Pernambuco com uma incidência de $15,1 \%$, entretanto são raros os relatos da forma clínica de linfossarcomas nesta região. A freqüência de linfossarcomas observada neste trabalho foi de $0,5 \%$ acometendo mais bovinos de idade entre três e oito anos, criados sobre manejo intensivo. Segundo a lite- ratura de 1\%-5\% dos bovinos soropositivos desenvolvem este tipo de neoplasma que é o mais comum na pecuária leiteira e isso se deve ao manejo constante, pois a principal forma de transmissão da doença é a horizontal (Braga \& Laan 2001). Para alguns autores, o aparecimento da LEB ocorre endemicamente com mais frequência a partir dos dois anos de idade, o que é atribuído ao longo período de evolução da doença (Ferrer 1979, Birgel et al. 1999, Smith 2006).

0 aparecimento dos sinais clínicos depende da localização do tumor nos órgãos e incluem distúrbios digestivos, cardiorrespiratórios e reprodutivos, acarretando perda de peso e debilidade geral. Para Bertone (1990) e Johnson \& Kaneene (1991), o aumento de linfonodos superficiais é comum, po- 
rém linfossarcomas podem ocorrer, também, em tecidos linfóides viscerais, comprometendo o sistema digestivo, causando obstruções e/ou úlceras, manifestando-se clinicamente por anorexia, timpanismo recorrente e perda de peso, conforme foi observado em sete casos deste trabalho. Manifestações neurológicas foram observadas em apenas um bovino. Esses sinais ocorrem quando há compressão da medula por um linfossarcoma causando andar cambaleante, ataxia, paresia e evolução para paralisia e decúbito permanente.

A literatura afirma que a laparotomia exploratória é eficiente para diagnóstico nos casos suspeitos de obstrução intestinal, nos quais a identificação de massas tumorais na cavidade abdominal facilita o diagnóstico. Porém, se a lesão estiver restrita a órgãos ou linfonodos viscerais o diagnóstico pode ser extremamente difícil (Miller \& Van der Maaten 1982, Smith 2006), como foi observada em três casos em que se fez necessária a intervenção cirúrgica para constatar a presença de massas tumorais no trato digestório. Segundo Smith (2006), em alguns casos, as massas tumorais que podem ser palpadas no abdômen são múltiplas e variáveis em tamanho, desde um ligeiro aumento até tumores que atingem $50 \mathrm{~cm}$ de diâmetro. Os linfonodos ilíacos internos e mesentéricos encontram-se envolvidos na maioria dos bovinos. Estes tendem a ser firmes, mas não duros, e podem parecer discretamente lobulados. A laparotomia exploratória é indicada como ferramenta para auxiliar no diagnóstico clínico em casos mais difíceis de transtornos gastrointestinais em que o tránsito está comprometido e os outros métodos semiológicos não foram suficientes.

Na necropsia os órgãos mais acometidos foram os linfonodos, abomaso e intestino, e os menos afetados coração, fígado, rins e útero (Quadro 2). Estes achados macroscópicos são semelhantes aos descritos na literatura, entretanto, alguns autores acrescentam que os linfossarcomas nos intestinos são raros, porém quando ocorrem, o segmento mais acometido é o intestino delgado. As lesões nos linfonodos podem ser multifocais ou difusas, sem distinção entre a medular e a cortical (Parodi 1987, Bertone 1990, Emanuelsson et al. 1992, Smith 2006, Barros 2007, Silva et al. 2008). Na forma entérica da doença há alargamento da submucosa do abomaso. Pode haver o envolvimento dos linfonodos mesentéricos, associados com a infiltração do abomaso, sendo que estes podem se apresentar com volume suficiente para causar obstrução (Valli 1993), conforme ocorrido em alguns animais desse estudo. Radostits et al. (2007) e Barros (2007) relatam a presença de massas tumorais de aspecto firme e de coloração branco-amarelada, em qualquer órgão, sendo que o abomaso, o coração e a medula são os órgãos geralmente envolvidos.

Segundo Parodi (1987) e Emanuelsson et al. (1992) as lesões nos órgãos reprodutores são pouco frequentes, podendo acometer útero e vagina, sem causarem distúrbios significativos. Diferentemente do observado em dois casos deste estudo, no qual a presença de uma massa tumoral extensa na região dorsal do útero provocou complicações no momento do parto, sendo necessária a realização de cesariana (Fig.1I).

Na LEB há, comumente, leucocitose persistente (LP), por linfocitose, que pode atingir valores acima de $100.000 / \mu \mathrm{L}$, além da presença de linfócitos atípicos na circulação (Radostits et al. 2007, Barros 2007). Neste trabalho, além da leucocitose de $34.082 / \mu \mathrm{L}$ por linfocitose foi constatada uma neutrófilia no leucograma. Os resultados obtidos por Azedo et al. (2008) permitem associar a manifestação da linfocitose persistente (LP) a uma atividade fagocitária reduzida dos linfócitos infectados, fato que pode ser explicado por uma maior quantidade relativa de linfócitos circulantes (Quadro 3).

Os achados da microscopia revelaram lesões e distribuição das mesmas similares às descritas na literatura, com células tumorais nos linfonodos, submucosa e serosa do abomaso, camada muscular e serosa do intestino, interstício da região cortical renal e coração (Yamamoto et al.1982, Bertone 1990).

Miller \& Van der Maaten (1979) recomendam que os bovinos positivos devam ser preferencialmente descartados para se evitar a disseminação no rebanho, foi o que aconteceu com 11 bovinos positivos que foram encaminhados para o abate. Entretanto, quando o descarte é economicamente inviável, nos casos de animais de alto valor zootécnico, a segregação dos soropositivos em grupos com manejo separado pode ser uma alternativa para reduzir a difusão da infecção.

\section{CONCLUSÃO}

Assim como em outras regiões do Brasil, no Agreste Meridional de Pernambuco o linfossarcoma como manifestação da leucose bovina enzoótica causa perdas econômicas, principalmente com o descarte de animais comprometendo sua vida produtiva e reprodutiva. É importante alertar os produtores dos cuidados que se devem ter para adquirir animais livres da doença, assim como da necessidade de implantar medidas que evitem a difusão da mesma nas fazendas.

\section{REFERÊNCIAS}

Afonso J.A.B. \& Costa N.A. 2007. Doenças não transmissíveis do trato digestivo dos ruminantes: obstrução intestinal em bovinos, p.370-371. In: Riet-Correa F., Schild A.L., Lemos R.A.A. \& Borges J.R.J. (Eds), Doenças de Ruminantes e Eqüídeos. Vol.2. 3ํㅗㄹ. ed. Palloti, Santa Maria.

Amoril J.G. 2005. Leucose enzoótica bovina: epidemiologia e diagnóstico em animais abatidos no Estado de Goiás. Jaboticabal, SP. Tese de Doutorado, Faculdade de Ciências Agrárias e Veterinárias, Universidade Estadual Paulista, Jaboticabal, SP. 161p.

Azedo M.R., Massoco C.O., Blagitz M.G., Souza F.N., Batista C.F., Sakai M., SáRocha L.C., Kfoury Junior J.R., Stricagnolo C.R., Benesi F.J. \& Della Libera A.M.M.P. 2008. Influência da leucose enzoótica bovina na função fagocítica de leucócitos circulantes em animais manifestando linfocitose persistente. Braz. J. Vet. Res. Anim. Sci. 45(5):390-397.

Barros C.S.L. 2007. Leucose bovina, p.159-168. In: Riet-Correa F., Schild A.L., Lemos R.A.A. \& Borges J.R.J. 2007. Doenças de Ruminantes e Eqüídeos. 3ㄹ ed. Volume-2, Palloti, Santa Maria, p.159-167

Bertone A.L. 1990. Neoplasms of the bovine gastrointestinal tract. Vet. Clin. North Am., Food Anim. Pract. 6(2):515-523.

Birgel Junior E.H., Dias W.M.C., Souza R.M., Pogliani F.C., Birgel D.B. \& Birgel E.H. 2006. Prevalência da infecção pelo vírus da leucose bovina em animais da raça Simmental, criados no Estado de São Paulo. Ars Vet. 22(2):122-129.

Birgel E.H., Ayres M.C.C. \& Birgel Júnior E.H. 1999. Prevalência da leucose enzoótica dos bovinos, em animais criados na bacia leiteira do Estado de Alagoas, Brasil. Anais 3o Congresso Brasileiro de Buiatria, São Paulo. Sociedade Brasileira de Medicina Veterinária, p.129.

Braga F.M. \& Laan C.W.V.D. 2001. Leucose enzoótica bovina, p.126-134. In: Riet-Correa F., Schild A., Méndez M.D.C. \& Lemos R.A.A. (Eds), Doenças de Ruminantes e Eqüinos. Editora Varela, São Paulo.

Burny A., Bruck C., Cleuter Y., Couez D., Deschamps J., Gregoire D., Ghysdael J., Kettmann R., Mammerickx M., Marbaix G. \& Portelle D. 1985. Bovine leukaemia virus and enzootic bovine leukosis. Onderstepoort J. Vet. Res. 52:133-144. 
Burny A., Cleuter Y., Kettmann R., Mammerickx M., Marbaix G., Portetelle D., Van den Broeke A., Willems L. \& Thomas R. 1988. Bovine leukaemia: Facts and hypotheses derived from the study of an infectious cancer. Vet. Microbiol. 17(3):197-218.

Curi P.R. 1997. Metodologia e Análise da Pesquisa em Ciências Biológicas. Tipomic, Botucatu. 263p.

Da Y., Shanks R.D., Stewart J.A. \& Lewin H.A. 1993. Milk and fat yields decline in bovine leukemia virus infected Holstein cattle with persistent lympho-cytosis. Proc. Natl Acad. Sci., USA, 90:6538-6541.

Dahlberg J.E. 1988. An overview of retrovirus replication. Adv. Vet. Sci. Compend. Med. 32:1-35.

D’Angelino J.L., Garcia M. \& Birgel E.H. 1998. Epidemiological study of enzootic bovine leukosis in Brazil. Trop. Annnals Health Product., Dordrecht, 30:13-15.

Dirksen G. 1993. Sistema digestivo, p.204. In: Dirksen G., Gründer H.D. \& Stöber M. (Eds), Exame Clínico dos Bovinos. 3aa ed. Guanabara Koogan, Rio de Janeiro.

Emanuelsson U., Scherling K. \& Pettersson H. 1992. Relationship between herd bovine leukemia virus infection status and reproduction, disease incidence, and productivity in Swedish dairy herds. Prev. Vet. Med. 12:121131.

Ferrer J.F. 1979. Bovine leukosis: Natural transmission and principles of control. J. Am. Vet. Med. Assoc. 175(12):1281-1286.

Ferrer J.F. 1980. Bovine lymphosarcoma. Adv. Vet. Sci. Comp. Med. 24:265.

Flores E.F., Weiblen R., Pereira N.M., Portolan J.A.B. \& Chielle L.L. 1988. Prevalência de anticorpos contra o vírus da Leucose Bovina (VLB) no rebanho leiteiro de Santa Maria, RS. Revta Centro Ciênc. Rurais UFSM 18(1):67-73.

Fubini S.L. \& Trent A.M. 2004. Small intestine surgery in cattle, p.240-256. In: Fubini S.L. \& Ducharme N.G. (Eds), Farm Animal Surgery. W.B. Saunders, St Luis. Missouri.

Hubner S.O., Weiblen R., Moraes M.P., Silva A.M., Cardoso M.J.L, Pereira N.M. \& Zanini M. 1997. Infecção intra-uterina pelo vírus da leucose bovina. Revta Bras. Reprod. Anim. 21(4):8-11.

Jain N.C. 1993. Essentials of Veterinary Hematology. Lea and Febiger, Philadelphia, p.17.

Johnson R. \& Kaneene J.B. 1991. Bovine leukemia virus. Part I. Descriptive epidemiology, clinical manifestations, and diagnostic tests. Compend. Contin Educ. Pract. Vet. 13(2):315-324.

Johnson R. \& Kaneene J.B. 1992. Bovine leukaemia virus and enzootic bovine leukosis. Vet. Bull. 62;287-312.

Leite R.C., Lobato Z.I.P. \& Camargos M.F. 2001. Leucose enzoótica bovina. Revta CFMV, Brasília, 24:20-28.

Matos P. F., Birgel Jr E.H. \& Birgel E.H. 2005. Leucose enzoótica dos bovinos: prevalência de anticorpos séricos em bovinos criados na Bahia e comparação entre resultados do teste de Elisa e imunodifusão em gel de Agar. Braz. J. Vet. Res. Anim. Sci. 42:171-180.

Melo L.E.H. 1991. Leucose enzoótica dos bovinos: prevalência da infecção em rebanhos leiteiros criados no Agreste Meridional do Estado de Per- nambuco. Dissertação de Mestrado, Faculdade de Medicina Veterinária e Zootecnia, USP, São Paulo. 102p.

Mendes E.I. 2002. Aspectos sorológicos e hematológicos como recursos auxiliares ao diagnóstico da Leucose Enzoótica dos Bovinos em rebanhos leiteiros de Pernambuco. Dissertação de Mestrado, Universidade Federal Rural de Pernambuco, Recife. 47p.

Miller J.M. \& Van der Maaten M.J. 1979. Infectivity tests of secretions and excretions from cattle infected with bovine leukemia virus. J. Natl Cancer Inst. 62(2):425-428.

Miller J.M. \& Van der Maaten M.J. 1982. Bovine Leukosis: Its importance to the dairy industry in the United States. J. Dairy Sci. 65:2194-2203.

Murphy F.A., Gibbs E.P.J., Horzineck M.C. \& Studdert M.J. 1999. Veterinary Virology. $3^{\text {rd }}$ ed. Academic Press, California. 4495p.

OIE 2001. International Animal Health Code. Office International des Epizooties, Paris. Disponível em <http:// www.oie.int/Norms/MCode/ htm> Acesso 1 mar. 2003.

Parodi A.L. 1987. Pathology of enzootic bovine leukosis: Comparison with the sporadic form, p.15-49. In: Burny A. \& Mammerickx M. (Eds), Enzootic Bovine Leukosis and Bovine Leukemia Virus. Martinus Nijhoff, Boston.

Radostits O.M., Gay C.C., Blood D.C. \& Hinchcliff K.W. 2007. Clínica Veterinária: um tratado de doenças dos bovinos, ovinos, suínos, caprinos e eqüinos. 9a ed. Guanabara Koogan, Rio de Janeiro, p.940-951.

Rangel N.M. \& Machado A.V. 1943. Contribuição à oncologia comparada em Minas Gerais. Arqs Esc. Sup. Med. Vet. Est. Minas Gerais, Belo Horizonte, 1:83-96.

Schwartz I. \& Levy D. 1994. Pathobiology of bovine leukemia virus. Vet. Res. 25(6):521-536.

Silva S.V. 2001. Leucose Enzoótica dos Bovinos: Prevalência de anticorpos séricos anti-Vírus da Leucose dos Bovinos em rebanhos cruzados holandês/zebu e em animais da raça Pé-duro, criados no Estado do Piauí. Tese de Doutorado, Faculdade de Medicina Veterinária e Zootecnia, USP, São Paulo. 176p.

Silva R.C., Fontana I., Meirelles F.C., Ruggiero A.P.M., Benato N. \& Borges J.R.J. 2008. Ocorrência de leucose enzoótica bovina na forma de linfossarcomas no distrito federal: relato de caso. Arqs Inst. Biológico, São Paulo, 75(4):507-512.

Smith B.P. 2006. Doenças do sistema hematopoiético e hemolinfático, p.1067-1070. In: Ibid. (Ed), Medicina Interna dos Grandes Animais. 3aㅗ ed. Manole, São Paulo.

Trainin Z., Brenner J., Meirom R. \& Ungar-Waron H. 1996. Detrimental effect of bovine leukemia virus (BLV) on the immunological state of cattle. Vet. Immunol. Immunopathol. 54(1/4):293-302.

Valli V.E.O. 1993. The hematopoietic system, p.101-265. In: Jubb K.V.F., Kennedy P.C. \& Palmer N. (Eds), Pathology of Domestic Animals. Vol.3. th $^{\text {th }}$ ed. Academic Press, San Diego.

Yamamoto H., Yoshino T., Matsuda I. \& Nakajima H. 1982. Histopathological definition of the adult and calf types of bovine leukosis. Natl Inst. Anim. Health Quart., Tokyo, 22(3):115-129. 